\title{
INFANCIA CAMPONESA: INTERACCIONES ENTRE CUERPO, NATURALEZA, TRABAJO, EDUCACIÓN Y CULTURA
}

Camponese childhood: interactions between the body, nature, labor, education and culture

Infância camponesa: interações entre corpo, natureza, trabalho, educação e cultura ${ }^{1}$

\section{Jaciara Oliveira Leite}

Faculdade de Educação Física e Dança da Universidade Federal de Goiás. Telf.:: (5562) 981379710. Correo electrónico: jacifef1@yahoo.com.br

\begin{abstract}
Ana Márcia Silva
Faculdade de Educação Física e Dança da Universidade Federal de Goiás. Telf.: (5562) 981158546. Correo electrónico: amarciasi@gmail.com

\section{Leila Chalub Martins}

Faculdade de Educação da Universidade de Brasília. Telf.: (5561) 999891564. Correo electrónico: leilachalub3@gmail.com
\end{abstract}

\section{Resumo}

Este texto analisa os espaços-tempo e práticas que caracterizam a vida de crianças camponesas residentes em uma comunidade rural localizada no Centro-Oeste brasileiro. Trata-se de um recorte da investigação de doutorado intitulada "Infância, Corpo e Educação do Campo". O trabalho orientou-se pela concepção de criança como sujeito social e, por isso mesmo, privilegiou a escuta e a observação das diferentes expressões das crianças por meio do emprego de estratégias lúdicas de pesquisa. Os instrumentos principais foram a observação participante e a entrevista. Da práxis investigativa, construída com e sobre as crianças, destacam-se: a infância constituída em interação com o bioma Cerrado; as relações entre as dimensões do corpo, natureza, cultura, trabalho e educação expressas nas atividades infantis e no cotidiano; e a resistência comunitária e das crianças para permanência digna no território camponês com escasso apoio do poder público.

\footnotetext{
${ }^{1}$ O presente trabalho recebeu apoio financeiro via Edital Auxílio à Pesquisa DPP-UnB No 02/2016 e do Projeto de Extensão "Terra encantada: gente miúda, direitos integrais" (UFG).
} 
Palavras-chave: infância, corpo, educação do campo.

\title{
Resumen
}

Este texto analiza los espacios-tiempos y las prácticas que caracterizan a vida de los niños en una comunidad rural no localizada en el Centro-Oeste brasileiro. Tratase de un recorte de la investigación de doctorado titulada "Infancia, Cuerpo y Educación del Campo". El trabajo se orienta por la concepción de niño como sujeto social y por esto mismo, privilegia una escucha y una observación de las diferentes expresiones de los niños por medio del empleo de estrategias lúdicas de investigación. Los instrumentos principales fueran observación participativa y entrevista. De la práxis investigativa, construida con y sobre los niños, se destacan: una infancia constituida en interacción con el bioma Cerrado; relaciones entre las dimensiones cuerpo, naturaleza, cultura, trabajo y educación expresas en las actividades infantiles y en el cotidiano; y la resistencia comunitaria y de los niños para permanencia digna en el territorio campesino con escaso apoyo del poder público.

Palabras clave: infancia, cuerpo, educación del campo.

\begin{abstract}
This text analyzes the space-time and practices that characterize the life of peasant children living in a caponese community located in the Brazilian Midwest. This is a cut of the doctoral research entitled "Childhood, Body and Field Education". The work was guided by the conception of child as a social subject and, therefore, privileged the listening and observation of the different expressions of the children through the use of ludic research strategies. The main instruments were participant observation and interview. Of the investigative praxis, constructed with and about the children, it can be highlighted: the childhood constituted in interaction with the Cerrado biome; the relations between the dimensions of the body, nature, culture, labor and education expressed in children's activities and daily life; and the community and children's resistance to a dignified stay in the peasant territory with scarce public support.
\end{abstract}

Key words: childhood, body, rural education. 


\section{Introdução}

Como é ser sujeito-criança no campo? O que as crianças dizem (em suas mais diversas linguagens) sobre suas vidas, seu lugar. Essas foram as questões centrais que inspiraram a pesquisa de doutorado intitulada provisoriamente "Infância, Corpo e Educação do Campo"2 . A investigação foi realizada em parceria com uma comunidade camponesa composta predominantemente por famílias de pequenos/as agricultores/as e que se localiza no estado de Goiás (GO), na região Centro-Oeste do Brasil. Este texto apresenta um recorte do referido trabalho, tendo por objetivo analisar os espaços-tempo e as práticas que caracterizam a vida das crianças que nela residem.

A relevância social da temática de investigação centra-se na urgência em romper com as tentativas históricas de invisibilidade, na academia e nas políticas públicas, do campesinato e, em especial, das crianças camponesas, buscando compreender seus modos de vida, anseios e saberes a partir, primordialmente, dos olhares e do que comunicam as próprias crianças.

A investigação soma-se aos esforços teórico-práticos e políticos de consolidação da Educação do Campo, que é uma política, prática e projeto de educação crítica ligada aos processos de produção da vida no campo e às lutas empreendidas pelos movimentos sociais por reforma agrária e pelo acesso a direitos fundamentais, como saúde e educação públicas e de qualidade no meio rural (Caldart, 2012).

Parte-se da concepção de que as crianças são sujeitos sociais que possuem proximidades em suas características biológicas, psicológicas e do modo como se relacionam com o mundo, principalmente por meio do brincar, do movimento (Arenhart, 2003) e da imaginação. Essas características, já muito estudadas e percebidas, não fazem da infância uma experiência igualmente vivida por todas elas, tão pouco que desfrutem de um mundo à parte da realidade social da qual também são integrantes.

A infância pode ser entendida como experiência e condição social geracional permeada por outras como classe, raça, etnia, gênero. É vivida num dado contexto

\footnotetext{
${ }^{2} \mathrm{O}$ doutorado está sendo realizado no Programa de Pós-graduação em Educação da UnB, sob orientação da prof. Leila Chalub Martins e co-orientação da prof. Ana Márcia Silva. A pesquisa de campo foi concluída em novembro de 2016. Teve aprovação no Comitê de Ética em Pesquisa em Ciências Humanas e Sociais (CEP/CHS) da UnB. Parecer n ${ }^{\circ}$ 2.010.482.
} 
sócio-histórico, o que contemporaneamente significa dizer na modernidade e no modo de produção capitalista (Sarmento, 2008; Arenhart, 2003; Leite, 2010; Silva, 2003). A criança é, então, o ser que vive essa complexa condição: a infância.

Para Carli (2011), podemos mesmo falar em infâncias, no plural, indicando sua diversidade e complexidade. Nesse sentido, pode-se dizer que a infância vivida no campo tende a ser diferente da vivida na cidade. Mesmo no meio rural, é possível observar que as filhas e filhos de agricultores/as familiares, quilombolas, acampados e assentados da reforma agrária, assalariados rurais e tantos outros ${ }^{3}$ convergem no modo de vida camponês, mas vivenciam as muitas peculiaridades do contexto cultural e desenvolvem suas subjetividades, conforme se verá na infância do território investigado, a Comunidade do Sertão (Alto Paraíso - GO).

\section{Infância e território}

"[...] Sertão é isto: o Senhor empurra para trás, mas de repente ele volta a rodear o Senhor dos lados. Sertão é quando menos se espera [...] O Sertão é do tamanho do mundo"

(Guimarães Rosa, 2001).

Quando se fala em Sertão no Brasil, o imaginário social tende a nos levar a um lugar longínquo, à estrada de terra, ao tempo lento, à pouca e sofrida vida; outras vezes pode remeter ao romantismo da tranquilidade da vida na roça. É importante ressaltar que foi o processo de construção histórica e social, desde os primórdios da colonização no país, que denominou o Sertão como o interior, um lugar a ser desbravado, dominado, deserto e em oposição ao litoral (Saraiva, 2006; Bertran, 2011).

Essa construção ajudou a produzir uma determinada concepção de campo que esconde as contradições de um país extremamente desigual e que tenta desconsiderar a existência dos/as camponeses/as, inferiorizando seus saberes, modos de vida, a própria natureza, e colocando-os a parte dos direitos fundamentais. Ao adentrar justamente em um território chamado "Comunidade do Sertão" foi possível perceber sua vida pulsante, tão singular e tão plural em sua complexidade.

\footnotetext{
${ }^{3}$ São consideradas populações do campo na legislação brasileira, além dos citados: [...] extrativistas, pescadores artesanais, ribeirinhos, caiçaras, povos da floresta, caboclos e outros que produzam suas condições materiais de existência a partir do trabalho no meio rural (Art. 1, párag. 1, item I. Decreto $\mathrm{n}^{\circ}$ $7.352,2010)$.
} 
Compreende-se a Comunidade do Sertão como um território. Para Fernandes (2006), o campo pode ser considerado território ou setor da economia, esse último restringi-o somente à produção de mercadorias. Entendê-lo como território exprime-o como espaço de vida e de desenvolvimento de todas as dimensões da existência humana. $\mathrm{O}$ autor ressalta ainda que a singularidade dos territórios camponês, com toda sua diversidade, é a organização por meio do trabalho familiar.

Acredita-se que "[...] apenas a partir da concepção de campo como lugar de vida (humana, da fauna e da flora. Digna.) que é possível articular: infância e campo" (SILVA et al. 2013: 16). (grifos das autoras).

A Comunidade do Sertão localiza-se no coração do Brasil, no município de Alto Paraíso, na Chapada dos Veadeiros no estado de Goiás. O território total tem cerca de $60 \mathrm{~km}$ de diâmetro. É um lugar dotado de terras férteis, de belas paisagens, presença de povos tradicionais e rica biodiversidade do bioma ${ }^{4}$ Cerrado.

De forma breve, o bioma Cerrado é o segundo maior do país, vindo logo após a Floresta Amazônica. Ocupa cerca de $22 \%$ do território nacional compondo mais de dez estados e é um tipo de savana. Ele abriga uma infinidade de rios, inclusive as nascentes das três maiores bacias hidrográficas da América do Sul (Amazônica/Tocantins, São Francisco e Prata). Possui uma rica biodiversidade, alimentos nutritivos, plantas medicinais e sua ocupação humana data de 11 mil anos. Muitas populações produzem sua existência no Cerrado, tais como: pequenos/as agricultores/as, etnias indígenas, quilombolas, geraizeiros, ribeirinhos, babaçueiras e vazanteiros (Bizerril, 2004; Brasil, 2017).

$\mathrm{Na}$ atualidade, o Cerrado e toda sua riqueza natural e cultural vem sendo ameaçada pelo avanço do agronegócio no Brasil, que é atrelado ao capital estrangeiro e tem o estado de Goiás como um de seus protagonistas no mercado mundial. Esse processo tem empreendido o desmatamento para a formação de latifúndios,

\footnotetext{
4 "As regiões secas da Terra estão divididas em grandes áreas chamadas biomas, cada um com determinadas combinações de clima, geologia e grupos de organismos relativamente estáveis. Os dois fatores mais importantes que determinam os tipos de plantas e animais encontrados em cada um desses biomas são a temperatura e o regime de chuvas" (Bizerril, 2004:14). O Cerrado é considerado um dos "hotspots" do mundo, o que significa que é rico em biodiversidade e encontra-se ameaçado de destruição (Idem).
} 
principalmente, para a composição de pastos para gado e monoculturas de soja, cana-deaçúcar e eucalipto, além do uso de veneno e modificações genéticas de sementes (transgenia), impactando diretamente em toda sociedade, mas com ainda maior incidência sobre as populações camponesas (Calaça, 2010; Oliveira, 2012; Rizzolo, 2015).

Em meio a esse alarmante e triste quadro, a Comunidade do Sertão situa-se em local privilegiado. A zona de amortecimento do Parque Nacional Chapada dos Veadeiros, Reserva da Biosfera, Área de Proteção Ambiental (APA - GO), e corredor ecológico Paranã - Pirineus passam pela comunidade (Rezende, 2010), o que garante a ela certa proteção quanto à degradação do Cerrado, tão presente no estado de Goiás, em decorrência do agronegócio.

A história da ocupação da Chapada dos Veadeiros remete aos ancestrais indígenas (do tronco linguístico macro-jê, entre outros povos), ao garimpo do ouro no século XVIII, à agricultura (policultural) e à pecuária extensiva, ao garimpo do cristal (início século XX), à coleta de flores do Cerrado, às comunidades tradicionais, à sustentabilidade (SARAIVA, 2006), à escravidão e sua resistência com os quilombos.

A Comunidade do Sertão é composta em sua maioria por pequenos/as agricultores/as. Há aproximadamente 300 (trezentos) moradores/as, sendo desses 50 (cinquenta) crianças (até por volta de doze anos de idade), segundo informações de uma moradora e educadora (Diário Camponês 1, março, 2015).

Entre os muitos elementos que constituem a comunidade, destacam-se aqui: seus saberes ancestrais sobre o Cerrado e, de forma geral, o manejo sustentável da natureza por parte dos/as moradores/as; a auto-gestão e resistência comunitárias dadas as dificuldades em acessar direitos básicos como saúde, educação, transporte público e abastecimento de água; e a busca e exercício da soberania alimentar.

Esse último aspecto trata da defesa de que o controle da produção dos próprios alimentos deve ser feito pelos/as camponeses/as, sendo esse fator fundamental para que as populações tenham garantido tanto o acesso aos alimentos em qualquer época do ano, como para que a produção seja adequada: "[...] ao bioma onde vivem, às suas necessidades nutricionais e aos seus hábitos alimentares" (Stedile e Carvalho, 2012: 722). 
Lugar chave para entender a realidade estudada e a infância é a Escola do Sertão, já que a instituição funciona como polo articulador e centro irradiador de atividades educacionais, políticas, culturais e sociais, tais como debates políticos, atividades de saúde (vacinação), votação eleitoral, festas, reuniões, aprendizados múltiplos...

Sua construção e manutenção tem sido fruto das ações comunitárias para garantir a educação formal pública, e é reveladora de um contexto histórico de adversidades, lutas e solidariedade (Rezende, 2010). Oferece da Educação Infantil (4 e 5 anos) ao Ensino Médio (a partir dos 15 anos), resistindo assim ao processo perverso de fechamento de escolas do campo no Brasil. Segundo os últimos dados da Frente Parlamentar em Defesa Educação do Campo (2015), somente no ano de 2014 foram fechadas 4084 instituições.

As escolas públicas do campo, como a do Sertão e tantas outras país afora, mesmo quando apresentam estrutura física inapropriada, acabam por se constituir como uma das escassas representações, física e simbólica, do poder público no meio rural. Funcionam como ponte de diálogo com a cidade, onde se localizam os órgãos administrativos do Estado, pois muitas vezes é via instituição escolar que as necessidades do campo chegam aos órgãos competentes.

Articulado aos sentidos e significados já apresentados, a escola é o espaçotempo privilegiado de encontro e de socialização das crianças na Comunidade do Sertão, principalmente, por conta das longas distâncias entre as moradias.

A existência da instituição escolar configura-se como uma das possibilidades concretas de permanência das famílias no campo, caso seja essa a sua opção, ao lado de outras condições como a garantia da terra e da água. Porém, mais do que a presença física da escola, que é fundamental, a Educação do Campo defende que os processos de ensino-aprendizado dos conhecimentos historicamente construídos estejam articulados à produção da vida e a um projeto de campo e de sociedade da classe trabalhadora. Para essa perspectiva todo o território camponês é considerado como educativo (Molina e Sá, 2012).

Nessa linha, a presente investigação foi desenvolvida com a permissão e em coparceria com os sujeitos, especialmente com as crianças da Comunidade e da Escola do 
Sertão ${ }^{5}$, em seus diferentes espaços-tempo, como a própria escola, as casas das famílias, os eventos culturais e as andanças com as crianças pela natureza, num processo de construção compartilhada do fazer investigativo.

\section{As crianças e a construção compartilhada da pesquisa: alguns princípios} teórico-metodológicos

Pesquisas com crianças no contexto comunitário rural revelam que elas sabem muito do lugar onde vivem, da geografia, do trabalho, do brincar, das pessoas e dos costumes culturais. Isso foi observado em grupos de crianças assentadas, as "sem-terrinha" pertencentes ao Movimento dos Trabalhadores/as Rurais Sem-Terra - MST, crianças de diferentes grupos camponeses - quilombolas, ribeirinhos, pescadores, agricultores familiares... (Silva et al. 2013), crianças indígenas (Nascimento et al. 2011), entre outros. Essas características foram perceptíveis também na comunidade participante desta pesquisa.

No total foram 10 (dez) viagens de campo, 5 (cinco) em 2015 e 5 (cinco) em 2016, com duração aproximada de 4 dias cada. Optou-se por trabalhar com "instrumentos lúdicos de coleta de dados", ou seja, com jogos, brincadeiras e maneiras lúdicas de interagir com as crianças, mesmo quando por meio de instrumentos mais usuais como a entrevista e a observação participante (Silva, 2009).

Os roteiros semi-estruturados de observação e entrevista buscaram contemplar aspectos da realidade relacionados às questões de pesquisa, apresentadas no início deste texto, e versaram sobre temas como: espaços e tempos que constituem o cotidiano infantil e também aqueles que fogem ao cotidiano; aspectos sociais, culturais e subjetivos das atividades realizadas pelas crianças e suas famílias, com foco nas brincadeiras e práticas corporais; interações: criança/criança, criança/adulto, composição de grupos; dilemas e sonhos do cotidiano da vida no campo segundo as próprias crianças; relações entre a realidade particular pesquisada e aspectos macro do

\footnotetext{
${ }^{5}$ A primeira autora deste artigo desenvolve relação de co-parceria com a referida comunidade desde 2013 em virtude do Projeto de Extensão Universitária "Terra Encantada: gente miúda, direitos integrais" (Sertão/UFG). As profundas e intensas experiências no Sertão junto com as crianças, no período da extensão, suscitaram as primeiras indagações que originaram a presente pesquisa. Ademais, a caracterização socioambiental da comunidade instiga reflexões sobre o atual quadro agrário brasileiro e os impactos para as famílias camponesas e para as crianças.
} 
campesinato brasileiro; conflitos; autonomia; grau de participação nas decisões familiares, escolares e na própria vida.

As intensas experiências vividas com as crianças extrapolam e integram-se aos aspectos previstos anteriormente nos roteiros, os quais constituíram-se em importantes guias para manter a coerência teórico-metodológica e a vinculação com o problema de pesquisa.

Com base nos estudos e na experiência vivida, destacam-se três princípios teórico-metodológicos que foram primordiais para as imersões em campo: o diálogo, a escuta sensível e o brincar. A articulação entre eles potencializou a vinda das crianças para o interior da investigação com mais organicidade, possibilitando acessar mais profundamente a infância em questão. Foram igualmente fundamentais para a formação humana e de pesquisa para as autoras.

O diálogo foi tomado como método de estudo, de pesquisa, de organização e como atitude. A inspiração veio das contribuições, sempre atuais, de Paulo Freire (1982: 107), que indagou: "E que é o diálogo? É uma relação horizontal de A com B. Nasce do amor, da humildade, da esperança, da fé e da confiança. Por isso só o diálogo comunica. E quando os dois polos do diálogo se ligam assim [...] se fazem críticos na busca de algo". Junto ao diálogo, a escuta sensível favoreceu "[...] apreciar o 'lugar' social de cada um no campo das relações sociais para poder escutar sua palavra ou sua ação 'criadora'" (Barbier, 2007: 95).

Muitas das vezes durante a pesquisa, os diálogos e a escuta sensível foram exercícios brincantes e corporais, simples, exigidos pelas próprias crianças, o que acabou transformando o próprio brincar com elas um princípio metodológico e que perpassou também aos instrumentos de pesquisa escolhidos. Tomando emprestadas as palavras de Arenhart (2016: 51):

[...] brincar com as crianças tornou-se, para mim, um pressuposto teórico e metodológico fundamental para conseguir afinar a percepção sobre as crianças da pesquisa, no intuito de buscar apreender sobre como elas se constituíam como sujeitos produtores de uma cultura própria, mobilizada, principalmente pelos processos interativos no interior das brincadeiras. 
Os instrumentos de pesquisa utilizados foram: observação participante, entrevista, desenho e fotografia. Todavia, neste texto nos ateremos somente aos dois primeiros. As observações participantes ocorreram por diferentes espaços-tempo do território do Sertão e seus registros compuseram os "Diários Camponês". Já as entrevistas ocorreram na escola, pois nela reúnem-se boa parte das crianças da comunidade, e foram coletivas de modo que a brincadeira pudesse ficar mais envolvente e que pudessem interagir entre elas e com a pesquisadora de campo.

Participaram das entrevistas por volta de 25 crianças entre 3 e 12 anos de idade. Elas eram convidadas e tinham autonomia para aceitar ou não, assim como sair quando desejassem. O envolvimento nas entrevistas variou em cada turma na escola, dependia de cada criança mas, de forma geral, pode-se dizer que se entregaram às brincadeiras. Eram entrevistadoras e entrevistadas, na brincadeira usamos câmeras e microfones inventados por elas mesmas, como pedaços de pau e pedra. Elas soltaram a voz e o corpo ao expressarem o que pensam e o que sentem sobre suas vidas no Sertão.

\section{Corpos brincantes: natureza, trabalho, educação e cultura}

"Na escola a gente brinca assim: quem acha mais jatobá (fruto do Cerrado) tem mais vida" (Guilherme, 7 anos, morador do Sertão).

Neste momento do texto apresenta-se a análise de algumas situações significativas protagonizadas pelas crianças e que trazem aspectos importantes para a reflexão sobre a infância em questão e o campesinato. A relação simples e complexa entre corpo, natureza, cultura, educação e trabalho emergiu como categoria de análise, visto que era constitutiva do cotidiano e das experiências infantis.

Nos diferentes espaços-tempo da comunidade, fosse na escola, nas casas dos/as moradores/as, nos encontros comunitários, nas conversas e brincadeiras partilhadas, essa relação estava na essência e se materializava nos limites físicos e simbólicos do território e na corporalidade de cada criança, de cada coletivo infantil.

A corporalidade como fenômeno social em sua totalidade, pode ser compreendida por essa relação entre o organismo, a perspectiva subjetiva, a cultura e o ambiente natural onde se constitui, marcando a construção das 
práticas corporais e de suas técnicas corporais de forma indelével (Silva; Silva e Tucunduva, 2011: 49).

Observando-as e brincando com elas no Sertão, consolidava-se ainda mais a noção de que as crianças estão profundamente conectadas com o mundo físico de seu corpo e ao seu redor, agindo no plano concreto e no tempo presente, como já analisou Wallon (2008).

A atitude de Manuela (4 anos de idade) numa situação de contação de histórias é exemplar nesse sentido:

À convite de Tia $^{6}$ Joana (professora da Educação Infantil da escola) fomos para um momento de contação de histórias com alguns livros. Sentamos, eu, ela e um grupo de crianças, embaixo da sombra das árvores no parquinho que fica no pé da serra. Manu começou a contar a história apontando para o livro. Passado alguns minutos, ela diz: - Eu não quero contar, eu quero fazer história, tia! Então, sai correndo e outras crianças a acompanham, brincando e contando corporalmente um enredo já conhecido deste grupo, com dragões, bruxas, bois. No meio da brincadeira ela para, rapidamente, de correr e diz: - Tia, eu quero brincar e fazer história! (Diário Camponês, agosto, 2016)

"Brincar e fazer história" tinha o sentido de não ficar parada contando ou escutando uma história, mas poder inventá-la e encenar os personagens criados por ela e seus colegas, movimentando-se livremente pelo espaço do parquinho, correndo em seu terreno irregular com pedrinhas e desníveis, entre suas árvores, com paus virando espadas e vassouras de bruxa. Os brinquedos construídos no parquinho, como balanço e escorregador, compuseram a brincadeira naquele momento como lugares onde os corpos desviavam, eram obstáculos brincantes. Alguns dos personagens por elas vivenciados são parte do cotidiano camponês, como o boi, outros são do faz-de-conta. Elas iam assim se entendendo corporalmente mesmo em meio aos conflitos, disputas e descontentamentos que também ocorriam.

\footnotetext{
${ }^{6}$ Chamar professora/educadora de "tia" é um hábito cultural ainda forte no Brasil. Remete à concepção e à história da educação, dentro e fora do contexto das escolas, como ofício feminino, maternal e desvalorizado socialmente. Freire (1997) discorre criticamente sobre a questão no livro "Professora sim, tia não: cartas a quem ousa ensinar".
} 
Benjamin (1985) trata do conceito de "mimesis" que pode ser entendida como a expressão da semelhança, uma "imitação" que possui o corpo como seu órgão mimético. Ao imitar sempre há uma (re)invenção e ressignificação do ato pelo próprio sujeito. O mesmo autor ainda informa que a brincadeira é que determina o conteúdo do brinquedo. É possível então compreender como paus, pedrinhas, árvores, balanços, escorregador, em outros momentos frutos do Cerrado, espaços e objetos tomavam outros sentidos para as crianças e eram a todo momento (re)inventados por elas, conforme será apresentado a partir de outras situações vivenciadas na pesquisa.

Ressalta-se que o ponto fundamental nesta discussão é que os elementos da imitação e do faz-de-conta que se expressam e compõe o brincar das crianças alimentam-se e exprimem o contexto cultural no qual as mesmas estão inseridas, sendo parte constitutiva do desenvolvimento dos sujeitos individual e coletivamente. Alguns dos personagens por elas vivenciados são parte do cotidiano camponês, tal como o boi, outros são conhecidos por meio das narrativas de faz-de-conta, como o dragão e a bruxa.

Trataram-se mesmo de experiências construídas pelas crianças, sujeitos sociais e históricos, e que são, como todos os seres humanos, capazes de trazer memórias de onde emergem os conteúdos das brincadeiras, ao mesmo tempo que recriá-las no presente (Benjamin, 1985). A realidade investigada, com seus limites e avanços, parece favorecer que as crianças se contraponham ao "[...] enfraquecimento da experiência coletiva no mundo do capitalismo moderno. [...] Na experiência, os elementos não estão perdidos e encontram-se imersos na corporalidade" (Silva et al, 2009: 15).

É possível analisar que, nessas interações construídas pelas crianças na relação entre corpo, natureza e cultura, o plano simbólico é projetado no plano concreto e viceversa, já que as criações infantis transcendem as condições objetivas por meio do fazde-conta, ao mesmo tempo que se dão sob essas mesmas condições.

Nesse sentido, foi observada uma simbiose entre as crianças do Sertão e os ciclos naturais, as estações, rios, fauna e flora do Cerrado e os modos de vida camponês que interferem, ou mesmo definem, muitas das atividades e práticas corporais por elas realizadas. 
As brincadeiras fluíam como o Rio São Bartolomeu, fundamental para esta e outras comunidades da região, lugar de travessia, lazer e trabalho. No auge da seca do ano de 2016, em agosto, um grupo de 4 crianças fizeram um convite para um passeio no Rio São Bartolomeu e proximidades. A umidade do ar baixa, por volta dos $15 \%$, e a alta temperatura típicas $\left(30^{\circ} \mathrm{C}\right)$ deste período do ano, fazem do rio um lugar ainda mais convidativo. O gosto por nele banhar-se é quase uma unanimidade entre as crianças.

Fomos para o rio com Grazielle (12 anos), Kalyel (11 anos), Guilherme (8 anos) e Elinha (10 anos). Abaixo um breve relato da aventura intitulada de "O jatobá":

(Grazielle sai do rio e vai até o pé de jatobá, que fica na margem. No chão há vários jatobás só aguardando para serem catados).

Kalyel: - Joga desse aí pra mim, pra mi (mim) quebrar... Elinha: - Jatobá! Gui: - Joga pra mim, Grazi!

(Invenção de criança: Grazi entra na água cheia de jatobás "flutuantes", mais de 10!!! Ela e Kalyel, que são os maiores do grupo, mergulham e pegam pedras no fundo do rio para quebrá-los. As pedras eram usadas por todos e contávamos com a ajuda dos mais experientes para abrir o jatobá. Para os menores, Elinha e Gui, havia ainda o desafio de ficar em pé, pois ali já era um pouco fundo para eles).

[...] Grazi: - É bom comer ele dentro da água, tia!

Pesquisadora de campo: - Molhado?

Kalyel: - Fica com gosto de abacate!

(Diário Camponês, agosto, 2016)

Naquele dia, comemos mais jatobá do que em toda vida! Uma das crianças grudou a massa feita de farelo e água nos dentes e sorriu, logo todas a imitaram. $\mathrm{O}$ ar faltava de tantas gargalhadas. Em seguida, nos levaram para ver um rastro de onça na beira do rio e demonstravam curiosidade em perceber se teríamos ou não medo. Destaca-se que aquela marca na terra, que passaria desapercebida, só ganhou sentido e significado quando as crianças informaram do que se tratava. 
Ainda nesse episódio, ressalta-se o desafio de nadar para Elinha que começou demonstrando medo de ir um pouco mais adiante no rio e, no seu próprio tempo, foi se permitindo vivenciar a água, muito motivada por todo o movimento do grupo, imitando seus pares, e pela presença de uma adulta, no caso a própria pesquisadora de campo, que também a incentivava.

É possível analisar que refrescar-se foi só uma das possibilidades de interação entre as crianças e o rio. Vários elementos podem ser ressaltados dessa vivência e puderam ser também identificados em outras situações observadas e vividas com as crianças. Destacam-se dois deles, o primeiro refere-se aos conhecimentos das crianças sobre o Cerrado e a região, nesse caso expresso em como catar, abrir e comer o jatobá, deslocar-se no rio e identificar um rastro de onça. Conhecimentos que só são possíveis porque a produção de suas existências se dá nesse bioma.

O segundo elemento diz respeito ao processo de aprendizado social por meio da imitação e da mediação feita pelos sujeitos mais experientes, condição que nessa situação foram assumidos pelas crianças mais velhas, de modo que os saberes citados, e outros, puderam ser apreendidos por todos (Vygotsky, 2010). Eram saberes que passavam pelo corpo, as técnicas corporais nas palavras de Mauss (1974).

Ressalta-se que, apesar da abundância de rios na Comunidade do Sertão, em algumas de suas regiões o abastecimento de água nas residências é precário, por vezes ainda é necessário deslocar-se por longa distância para buscá-la nos rios. Além disso, alguns de seus trechos secaram. São dificuldades para acessar o básico e imprescindível para a existência humana, para suprir as necessidades fundamentais do organismo, para uso pessoal e familiar nas casas e que afeta também centralmente a produção de alimentos e a criação de animais. Isso torna a vida, que já é árdua durante o período (6 meses) de pouca ou de estiagem da chuva, que é característico do Cerrado (6 meses), ainda mais desafiante.

Outra atividade significativa entre as crianças era a de andar na mata para procurar e coletar frutinhas do Cerrado, era como uma aventura baseada nos ciclos da natureza e no conhecimento passado de geração em geração. Aguardar o período da florada, depois o aparecimento dos frutos, em seguida seu amadurecimento e, na maioria das vezes, esperar até que caíssem ao chão (sinal típico deste bioma de que 
estavam no tempo de colheita), para então se embrenhar no mato e encher-se deles, esse era o movimento. Assim acontecia com o cajuzinho-do-cerrado e o jatobá em agosto e setembro, a cagaita em outubro, a mangaba em novembro, e tantas outras.

Como afirmou Tiriba (2005: 191): "Pois as crianças vão construindo conhecimentos, valores, afetos a partir de sua experiência com o mundo. Experiência vivida num universo de corpos que tocam, olham, cheiram, comem, escutam. Corpos que sentem o mundo, leem o mundo [...]".

Analisa-se que viver a infância num território camponês em que os rios estão limpos, as árvores estão de pé e no qual as famílias produzem, com todas as dificuldades e contradições, a sua existência, como se percebe na Comunidade do Sertão, desdobra-se em possibilidades concretas de experenciar o próprio corpo e de se constituir como sujeito-criança mais integrado à natureza.

Essa maneira distingue-se do paradigma moderno da relação ser humano, corpo e natureza, pautado na fragmentação de ambos e no distanciamento do ser humano de si mesmo e de outras formas de vida. Ao mesmo tempo que parece se aproximar de concepções holísticas, como a cosmovisão indígena das Américas, ainda na atualidade, e a ideia de physis para os gregos, na Grécia antiga, na direção que indicamos abaixo.

Kaká Verá Jecupé (2002: 112), indígena da etnia guarani apresenta uma simbiose entre corpo, natureza humana e natureza: "Somos tecidos da terra, do fogo, da água e do ar. [...] Somos tecidos do tecido que tece a própria Mãe (grande mãe, mãe Terra) e tudo que criamos vem dessa mesma trama". Em entrevista ele esclarece:

[...] a história antiga de todas as etnias, dos mais diversos povos, o que todos tem em comum é uma incrível habilidade para interagir com aquilo que é chamado de ecossistema. Para esses povos, o ecossistema é uma entidade, uma inteligência viva [...] muito povos, para não dizer todos, fundem os seus mitos de origem, as suas histórias de origem [...] com as inteligências fundadoras.

Já para os gregos, o termo physis indicava a interligação permanente entre todos os seres e era também visto como sinônimo de natureza que seria: "[...] uma essência que se mantém e que, ao mesmo tempo, produz uma identidade, uma irmandade entre todos os seres" (Silva, 2006: 39). 
Para refletir sobre a relação corpo-infância parte-se aqui da perspectiva de que a interação natureza (humana) e cultura não é de dominação da primeira pela segunda, ou seja, da dimensão cultural sobre a biológica, ou para as teorias biologicistas o contrário (Buss-Simão et al, 2010), mas sim dialética, o que vale também para interações com a cultura de forma mais ampla.

O movimento dialético da realidade, pautado pela luta de classes como aspecto marcante do capitalismo, desafia e, em muitos momentos, amplia o afastamento já observado entre ser humano e natureza. Os mesmos corpos que se descobrem nas brincadeiras são oprimidos pelas contradições cotidianas de se viver em uma comunidade camponesa que faz parte de um processo de desvalorização da vida humana e não humana.

A Comunidade do Sertão enfrenta dificuldades ligadas aos ciclos naturais e à ausência do Estado, uma delas é a já citada falta de abastecimento de água em todas as casas, principalmente durante o extenso período de seca. A segunda refere-se as condições inadequadas da rodovia de terra que se acentuam no período de chuva e no auge da seca, impactando fortemente no deslocamento das pessoas e no já longo trajeto das crianças até a escola. Com a estrada em condições "normais", as crianças, jovens e trabalhadoras da instituição que moram mais distante podem passar até 8 horas por dia dentro do transporte escolar, sendo 4 horas para ir e mais 4 para voltar.

Ao serem perguntadas sobre o que precisa de melhorar na comunidade, a resposta das crianças é quase uma só, como nas palavras indignadas de Malu (11 anos): - "O ônibus e a estrada, tá muito buraquenta”! (Entrevista, maio, 2016). São esforços diários para viver o direito de estudar e de encontrar seus pares, já que a escola é o principal espaço-tempo de sociabilização entre as crianças na modernidade, ainda mais quando as distâncias entre as casas são significativas, como no Sertão. Os corpos cansados e sonolentos, em alguns casos agitados, eram notórios no interior do transporte escolar e nas atividades da escola (Diário Camponês, abril, 2015).

Imersas nesse contexto, as crianças subvertem os desafios diários, sentem e expressam as dificuldades vividas, participam do cotidiano de suas famílias, brincam... Ressalta-se que as atividades ao ar livre e envolvendo movimento puderam ser entendidas como as de suas preferências, tanto no período da seca quanto da chuva. A 
interação com a natureza apareceu de forma marcante na análise sobre a relação das crianças com o trabalho da família.

O trabalho revelou-se como dimensão fundamental do processo de desenvolvimento das crianças e como uma das características da infância camponesa analisada, ou melhor dizendo, reafirmou-se, já que é elemento enfatizado em diferentes estudos sobre as infâncias no contexto rural (Antunes-Rocha, 2013). Compõe, assim, a corporalidade das crianças na interconexão entre natureza e cultura.

Para Marx (2008; 2007), é por meio do trabalho que o ser humano transforma a natureza e é por ela transformado, conseguindo assim suprir suas necessidades orgânicas e sociais. Os valores e a organização do modo de produção capitalista acabaram por ressignificar o trabalho como algo em que o sujeito não se reconhece nele e que é penoso, sobretudo, para a classe trabalhadora. É o trabalho alienado.

A recuperação do sentido ontológico de trabalho em Marx possibilita compreender a articulação entre infância e trabalho, tão importante para o campesinato, e que pode ser mal compreendida se confundida com a nefasta exploração do trabalho infantil, invisibilisando, assim, as diferentes percepções e interações que as crianças têm com essa atividade humana. De forma precisa, Arenhart (2003: 135) contribui para esse debate ao esclarecer que:

[...] as crianças trabalham e isso não chega a ser problema para o direito à infância, desde que o tipo de trabalho que realizam não as aliene da condição de sujeitos e de crianças. Para isso, somente um trabalho que não seja alienado, que não as limite de vivenciar outras experiências humanas, como o estudo e a brincadeira que é própria da infância, pode ser aceitável.

A pesquisa demonstrou que as crianças trabalham, especialmente, ajudando sua família nos afezeres domésticos, na roça e acompanhando-a nos serviços da fazenda. A ligação das crianças desde bem pequenas com o trabalho é notória no Sertão. É o caso de Heitor (3 anos de idade) que aprecia coletar os ovos junto com sua avó, pega-os com todo cuidado e destreza, gosta muito quando aparece algum azul e, ademais, ele tem 1 galinha e demonstra orgulho por isso. Já Bruna ( 5 anos), certa vez mostrou um desenho que havia feito e explicou que seu programa favorito era ordenhar as vacas junto com o pai. 
$\mathrm{Na}$ brincadeira de entrevista coletiva, quando perguntadas sobre o trabalho de seus familiares, as crianças da turma do $2^{\circ} / 3^{\circ}$ ano ( 7 e 8 anos de idade) colocaram-se, por vezes, como parte desse trabalho:

Pesquisadora de campo: E você, Gui, no que sua família trabalha?

Rafa: Eu sei que o pai dele gosta de ficar pegando madeira.

Gui: É mermo (mesmo), ajudo meu pai pegá (pegar) lenha e por no caminhão e minha mãe fica lavando vasia (vasilha), e eu ajudo também.

Fred: Eu ajudo meu pai mexer com gado e pai dirige trator. Ajudo a mãe lavar louça de vez em quando.

Jorge: Lavar as vasia e também ajudo o pai a abrir as cancelas.

Kálita: Eu ajudo limpar casa, limpar fogão, lavar as roupas.

(Entrevista, novembro, 2016)

A fusão entre trabalho e brincadeira constituiu-se como elemento central. Chama-se "fusão" quando já ficava confuso saber se as crianças se referiam ao trabalho da família, à uma tarefa ou à uma brincadeira, onde um começava e outro terminava. $\mathrm{O}$ papo com Rafaela (5 anos) durante um banho de rio no São Bartolomeu exprime essa percepção:

Rafa nos contou que ganhou uma mula e estava bem feliz, que a mula era mancinha e tranquila. [...] Perguntei a ela sobre seus finais de semana...Ela me falou que acorda bem cedo junto com o pai, o ajuda no curral, solta os bezerros e que gosta muito de fazer isso. Depois dessas atividades, vai brincar com o cachorro e depois vai tomar café. [...] E fica o dia inteiro andando de bicicleta (Diário Camponês, setembro, 2016).

O trabalho como "estratégia de manifestação lúdica", associada às experiências com os elementos naturais, próxima aos familiares e com seus pares, foi observada, outrossim, em outros estudos sobre as infâncias camponesas (Arenhart, 2003; AntunesRocha, 2013), indicando que as crianças tendem a ressignificá-lo e vivenciá-lo de forma distinta do adulto. 
Diante de certa autonomia, ao mesmo tempo da opressão vivida no cotidiano comunitário do território em questão, os corpos brincantes das crianças deixaram manifestas as conexões entre natureza, cultura, trabalho e educação.

\section{Considerações finais}

O avanço do capitalismo aprofundou a separação ser humano e natureza, porém há contradições no movimento dialético que indicam outras formas de vida em simbiose em tempos em que o modo de viver urbano é o centro. $\mathrm{O}$ capitalismo anuncia que civilização é sinônimo de vida fora da natureza, dominando-a e buscando assegurar para as comunidades tradicionais um lugar de marginalidade, atraso, invisibilidade e desaparecimento.

Se, de forma hegemônica, essa concepção de natureza e da relação do ser humano consigo mesmo e com o planeta se intensifica, resistem formas de se viver e processos educativos imbuídos de outro tipo de conexão. Nas palavras de AntunesRocha (2013: p. p. 9 - 10):

Os desafios para uma vida digna estão colocados, a beleza da experiência de ser criança em relação cotidiana com os elementos da natureza estão presentes, mas não como dicotomias, como isso ou aquilo. E sim, como possibilidades concretas de produzir uma existência materializada na luta por direitos e por uma vida digna.

Essa forma outra de viver a infância e de constituir-se como sujeito social, só pode ser ampliada e aprofundada se as pessoas tiverem condições objetivas de permanecer e contribuir com o desenvolvimento de seus territórios e de suas famílias. $\mathrm{O}$ que somente será possível com seus direitos assegurados, com participação efetiva e democrática do Estado, e se o Cerrado ficar de pé e os rios livres de agrotóxicos para essa e para as gerações futuras.

Por fim, ressaltamos que o presente texto, obviamente, não conseguiu abarcar toda a complexidade e profunda vivência na comunidade em questão, nem tão pouco tem a pretensão de estender as análises para a diversidade de infâncias camponesas. Acreditamos que as reflexões aqui expostas possam contribuir para o fortalecimento de infâncias dignas no campo e na cidade. 


\section{Referências Bibliográficas}

Arenhart, D (2016). Culturas Infantis e Desigualdade Sociais. Petrópolis, RJ: Vozes. - (2003). A mística, a luta e o trabalho na vida das crianças do assentamento conquista na fronteira: significações e produções infantis. Dissertação de Mestrado. Programa de Pós-graduação em Educação - UFSC.

Antunes-Rocha, Maria Isabel. Prefácio. En: Silva, I. et al (org.). Infâncias do campo. (pp. 9-11). Belo Horizonte: Autêntica Editora, 2013. (Coleção Caminhos da Educação do Campo).

Barbier, R. (2007). A pesquisa-ação. Tradução de Lucie Didio. Brasília: Liber Livro Editora.

Benjamin, W. (1985). A doutrina das semelhanças. In: Obras escolhidas (vol. I) São Paulo, Brasiliense. . Magia e Técnica, Arte e Política. (1985) In: Obras escolhidas (vol. I) São Paulo: Brasiliense.

Bizerril, M. (2004). Vivendo no Cerrado e aprendendo com ele. São Paulo: Saraiva.

Bertran, P. (2011). História da Terra e do Homem no Planalto Central: eco-história do Distrito Federal, do indígena ao colonizador. $3^{\text {a }}$ ed. Brasília: Editora Universidade de Brasília.

BRASIL. Decreto n ${ }^{0}$ 7.352. Política Nacional de Educação do Campo e Programa Nacional de Educação na Reforma Agrária (PRONERA). 2010 .

BRASIL. (2017). O Bioma Cerrado. Ministério do Meio Ambiente - MMA. Disponível em: http://www.mma.gov.br/biomas/cerrado Consulta realizada 25 abr 2017.

Buss-Simão et al. (2010). Corpo e infância: natureza e cultura em confronto. Educação em Revista, 26, 03, 151-168.

Calaça, M.; Dias, W. (2010). A modernização do campo no cerrado e as transformações socioespaciais em Goiás. Campo-território: Revista de Geografia Agrária, 5, 10, 312-332.

Caldart, R. Educação do Campo (2012). En: Caldart, R. et al (orgs.) Dicionário da Educação do Campo. (pp. 259-267). Rio de Janeiro: Expressão Popular. 
Carli, S. (2011). La memória de la infancia: estudios sobre historia, cultura y sociedad. Buenos Aires: Paidós.

Fernandes, B. M. (2006). Os campos da Pesquisa em Educação do Campo: espaço e território como categorias essenciais. En: MOLINA, Mônica Castagna (org.). Educação do Campo e Pesquisa: questões para reflexão. (pp. 27-39). Brasil. Ministério do Desenvolvimento Agrário. Brasília, DF: Ministério do Desenvolvimento Agrário.

Freire, P. (1997). Professora sim, tia não: cartas a quem ousa ensinar. São Paulo: Editora Olho D'Água. . (1982). Educação como prática da liberdade. 13 a ed. Rio de Janeiro: Paz e Terra.Frente Parlamentar em Defesa Educação do Campo (2015). Fechamento das Escolas do Campo: dados 2014. 2015.

Guimarães, R. (2001). Grande Sertão: Veredas. 19ª ed. Rio de Janeiro: Nova Fronteira. Jecupé, K. (2002). Todas as vezes que dissemos adeus. $2^{\mathrm{a}}$ ed. São Paulo: TRIOM. . Entrevista ao Programa Roda Viva. Disponível em: Consulta realizada em 09 de janeiro de 2017. https://www.youtube.com/watch?v=iwU5KNMf014

Leite, J. (2010). A educação do corpo de crianças e jovens: um estudo de caso no cotidiano de um abrigo. Dissertação de Mestrado. Programa de Pós-graduação em Educação - UFSC

Marx, K. (2008). O Capital - crítica da Economia Política. Trad. de Reginaldo Sant'Anna. 25ª ed. Rio de Janeiro: Civilização Brasileira.

Mauss, M. (1974). Técnicas Corporais. En: Sociologia e antropologia (pp 211-233). São Paulo: Cosac \& Naify.

Molina, M. C.; SÁ, L. (2012). Escola do Campo. En: Caldart, R. et al (orgs.) Dicionário da Educação do Campo. (pp. 324-331), Rio de Janeiro: Expressão Popular.

Nascimento, A. (org.). (2011). Criança indígena: diversidade cultural, educação e representações sociais. Brasília: Liber Livro.

Oliveira, A. (2012). A mundialização da agricultura brasileira. XII Colóquio Internacional de Geocrítica, Bogotá. Anais....Bogotá: Universidade Nacional de 
Colômbia, Facultad de Ciencias Humanas, Departamento de Geografía, 2012. p. 1-15. Consulta realizada em 19 jul 2015 http://www.ub.edu/geocrit/coloquio2012/actas/14-A-Oliveira.pdf $>$.

Rezende, D. (2010). Conquistas comunitárias da gestão participativa na Educação do Campo: o caso da Escola do Sertão na Chapada dos Veadeiros - GO. Dissertação de Mestrado. Centro de Desenvolvimento Sustentável - UnB.

Rizzolo, A. (2015) Agrotóxicos e Soberania Alimentar. Palestra proferida na II Jornada Universitária em Apoio à Reforma Agrária - UnB.

Sarmento, M. (2002). Infância, exclusão social e educação como utopia realizável. Educação, Sociedade e Culturas, 17, 13-32.

Saraiva, R. (2006). Tradição e Sustentabilidade: um estudo dos saberes tradicionais do cerrado no Chapada dos Veadeiros, Vila São Jorge - GO. Tese de Doutorado. Centro de Desenvolvimento Sustentável - UnB.

Silva, M. (2009). Eventos-Campos: Um relato da experiência do fazer investigativo com crianças da Zona da Mata Canavieira Pernambucana. En: Faria et al (orgs.). Por uma cultura da infância: metodologia de pesquisa com crianças. $3^{\mathrm{a}}$ ed. Campinas, SP: Autores Associados.

(2003). Trama doce-amarga: (exploração do) trabalho infantil e cultura lúdica. Ijuí: Ed. Unijuí; São Paulo: Hucitec.

Silva, A. M. (2006). A natureza da PHYSIS HUMANA: indicadores para o estudo da corporeidade. En: SOARES, Carmen. Corpo e história. $3^{\mathrm{a}}$ ed. Campinas, SP: Autores Associados. (Coleção Educação Contemporânea).

silva, A. M.; silva, A. P. S.; Tucunduva, T. (2011). Corpo, cultura e natureza em Terras Quilombolas. En: Silva, A.; Falcão, J. (Org.). Práticas Corporais em Comunidades Quilombolas de Goiás.74ed. Goiás: PUC Goiás.

Silva, A. et al. (2009) Corpo e experiência: para pensar as práticas corporais. In: Falcão, J.; Saraiva, M. (Org.). Práticas Corporais no contexto contemporâneo: (in)tensas experiências. Florianópolis: Copiart. 
Silva, I. et al (org.). (2013) Infâncias do campo. Belo Horizonte: Autêntica Editora. (Coleção Caminhos da Educação do Campo).

Stedile, J. P.; Carvalho, H. (2012) Soberania Alimentar. En: Caldart, R. et al (orgs.). Dicionário da Educação do Campo. (pp. 714-724) Rio de Janeiro: Expressão Popular.

Tiriba, L. (2005). Crianças, natureza e educação infantil. Tese de Doutorado. Departamento de Educação da Pontifícia Universidade Católica do Rio de Janeiro.

Wallon, H. (2008). Do ato ao pensamento: ensaio de psicologia comparada. Petrópolis: Vozes. 